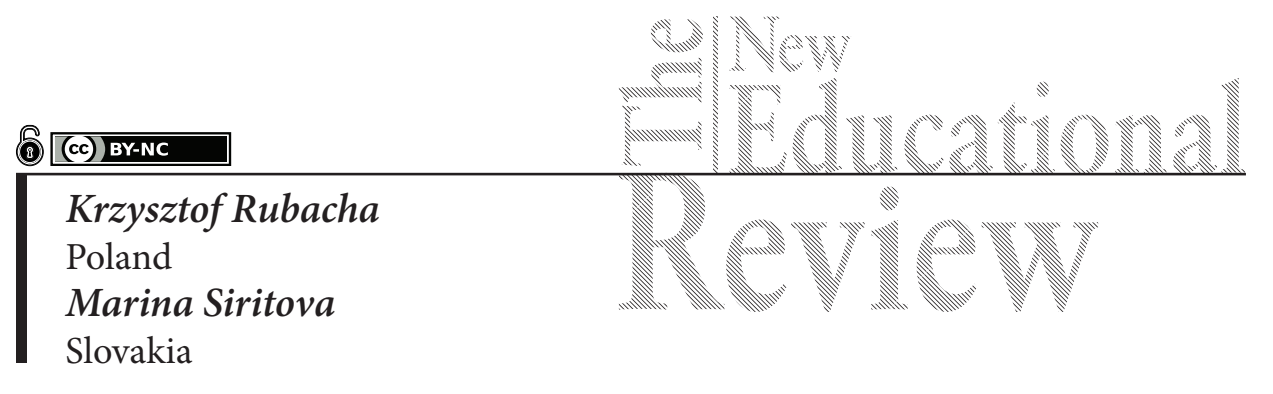

\title{
The Sense of Didactic and General Self-efficacy in Literature Teachers in Poland and Slovakia
}

DOI: 10.15804/tner.2019.55.1.21

\begin{abstract}
This paper discusses the results of a study of the sense of efficacy in literature teachers working in Poland and Slovakia. The findings presented in this paper show no difference registered in both types of the sense of efficacy when comparing teachers from each of the countries examined. The second result obtained amounted to a statistically significant difference between the general sense of efficacy on the one hand and the didactic sense of efficacy on the other. The mean for the sense of didactic efficacy is higher than for the general sense of efficacy. The results are subsequently referred to A. Bandura's analyses within the framework of a socio-cognitive theory.
\end{abstract}

Keywords: teachers' sense of efficacy, literature teachers in Poland and Slovakia, socio-cognitive theory

\section{Hypotheses}

The sense of efficacy, meaning an individual's assessment of his/her ability to meet the demands of different life-tasks, is a variable that explains the effectiveness of one's actions in many areas of human behavior. Research on self-efficacy generally presents the reader with two definitions, the first of which pertains to specific situations; engaging the individual's concrete resources to solve problems. There can be as many of these types of sense of efficacy as there are types of distinguishable and definable activities (Bnadura 1986, 1994). With regard to teachers, 
we can talk of the didactic sense of efficacy when we are interested in estimates as to the chances of completing complex tasks that arise in the course of one's daily teaching activities. Understood in this way, the sense of efficacy can also relate to an individual's assessment of his/her chances of accomplishing tasks that require effective use of a foreign language in concrete communicative situations. It seems that one is justified in trying to work out as many types of sense of efficacy as there are types of activities that can be described as either effective or ineffective. In this context, for one study participant we can register different levels of the sense of efficacy when they take up different tasks, because the factors that condition these levels are the individual's previous experiences, as well as their self-appraisal as to their competence in different areas.

A second approach to the sense of efficacy is to treat this variable as general, as largely immune to the effects connected with different types of activity. The general sense of efficacy is treated as a particular configuration of personal resources, such as perseverance, a sense of self-agency, belief in one's own abilities, the ability to delay gratification, the ability to translate goals into a plan of action, resistance to stress and frustration, developmental motivation, and inner-direction (Cervone, Pervin 2016). A large concentration of these variables causes the individual to exhibit a high sense of efficacy in his/her actions, regardless of which areas they are performed in. A lack of belief in one's own abilities, e.g., reveals itself in equal degree in all life situations.

These two contrasting approaches create theoretical difficulties, leaving doubt as to the true character of the sense of efficacy. One of the ways in which to deal with the difficulties is to undertake studies dedicated to both types within the scope of one research project. This article attempts to do just that with regards to the general sense of efficacy and didactic efficacy in teaching literature. With this goal in mind, we perform a measurement of both types of sense of efficacy in literature teachers. If we register a difference between the two types, we will have reinforced the hypothesis about the soundness of differentiating them theoretically, as is common practice when it comes to literature and research on the subject. Our research, however, examined teachers from two different countries, so as to also verify the hypothesis on the relative immunity of the sense of efficacy to social factors. According to A. Bandura (1994), the sense of efficacy does not depend on external conditioning, e.g., conditioning the teacher by the education system. Because we wanted to verify Bandura's claim, for our study we chose a sample from Poland and Slovakia, for the simple reason that these two countries differ significantly as to the development of their university systems, which prepare teachers for their future profession. Students in Poland are required to complete several times fewer credit 
hours of pedagogical and psychological classes than their Slovakian counterparts. If we were to record a difference in the sense of didactic efficacy between the two groups, we could indicate as a hidden factor the way teacher training is organized. One might expect that the more extensive system would give its students a higher sense of security, a higher sense of work readiness, than the much less developed system, which could possibly cause a sense of uncertainty in the face of complex educational tasks.

\section{Method}

Our study was conducted using a quasi-experimental design, in which we compared two groups of students with regard to the general and didactic senses of efficacy (independent samples) as well as the means of both types of sense of efficacy (dependent samples). The samples were made up of Slovakian philology students in Slovakia and Polish philology students in Poland. Each of the participants had completed several teacher placement schemes, teaching their native languages respectively, while the majority of the participants were already in-service teachers. The random variable in the independent samples was made up of each type of sense of efficacy, while the fixed variable was characterized by membership of the Polish or Slovakian group.

We measured the general sense of efficacy using two versions of the Sense of Efficacy Test [TPS - Test Poczucia Skuteczności], Polish and Slovakian versions. The Polish version is the original, while the Slovakian version was an adaptation. The test consists of 17 items, whose discriminatory power in the Polish version, measured with the point-biserial correlation coefficient, ranges from 0.26 to 0.86 . Reliability, calculated with the use of Cronbach's alpha, was between 0.87 and 0.89 for specific items. Theoretical validity was confirmed with the use of factor and cluster analyses and the test also calculated sten norms. The discriminatory power of items in the Slovakian version ranges from 0.34 to 0.75 according to the point-biserial correlation formula. Reliability, calculated with the use of the Spearman-Brown coefficient, amounted to 0.84 for the entire test. Factor analysis confirmed the theoretical validity of the tool. Instead of calculating the sten norms, the raw scores were normalized using the mean and standard deviation. (Chomczyńska-Rubacha, Rubacha, 2013). The variable discussed is, therefore, measured on the interval scale in both samples.

Following A. Bandura, the sense of didactic efficacy was measured micro-analytically, The participants were given a description of three difficult didactic 
situations connected with teaching the following aspects of Slovakian or Polish: grammar, elements of literary theory, and literary text analysis. Each of the situations was designed as a critical event in the classroom setting. The participants had to give a scaled-response to the question to what degree they would manage in these situations during their work placement. The data obtained was introduced into the arithmetic mean, increasing this measurement to the interval level.

The analysis was conducted for random samples of student-teachers on teacher placement from Slovakia $(\mathrm{N}=44)$ and Poland $(\mathrm{N}=37)$. In order to verify the hypotheses, two Student's t-tests were planned. As regards the samples from Poland and Slovakia, the t-test was used with the two independent samples, while with regard to comparing means of both types of sense of efficacy, a test of the dependent samples was used. Unfortunately, the homogeneity of variance was not met for either of the measurements. Therefore, the t-test for the independent samples was replaced by the nonparametric Kruskal-Wallis test of variance.

\section{Results}

The data obtained from our analysis shows that, in accordance with our expectations, the differences between the Polish and Slovakian samples turned out to be statistically insignificant. This result allows us to strengthen Bandura's hypothesis as to the relative independence of the sense of efficacy from - in our case - the scope and intensity of pedagogical training for teachers, which in Slovakia is significantly more advanced than in Poland. This data pertains to the general sense of efficacy as well as the sense of literature teachers' didactic efficacy.

Table 1. The null-hypothesis test for Polish and Slovakian samples for the Sense of Efficacy Test and the Sense of Didactic Efficacy Test

\begin{tabular}{llll}
\hline \multicolumn{1}{c}{ Null-hypothesis } & \multicolumn{1}{c}{ Test } & Significance & \multicolumn{1}{c}{ Decision } \\
\hline $\begin{array}{l}\text { Distribution for TPS is iden- } \\
\text { tical for both samples }\end{array}$ & $\begin{array}{l}\text { Kruskal-Wallis for } \\
\text { independent samples }\end{array}$ & .112 & Accept null-hypothesis \\
\hline $\begin{array}{l}\text { Distribution for PSD is iden- } \\
\text { tical for both samples }\end{array}$ & $\begin{array}{l}\text { Kruskal-Wallis for } \\
\text { independent samples }\end{array}$ & .166 & Accept null-hypothesis \\
\hline
\end{tabular}

Source: own research

This, however, is not a stable result, since in a another previous study a difference in the sense of teachers' educational efficacy from both countries was found, in favor of the Polish sample (Rubacha, Sirotova, 2013). The interpretation of 
that result was difficult because the group with the weaker pedagogical training revealed a higher sense of educational efficacy, along with an identical sense of general efficacy. At that time, we explained this phenomenon citing the possibility that students who are better trained for pedagogical work see more potential difficulties in this line of work, of which they are more aware. This is because they have had the chance to delve deeper into the complex educational processes at the theoretical level. The Polish students, on the other hand, were more naïve because they were less prepared. The presented result is easier to interpret. In line with Bandura's claims, the sense of efficacy depends mainly on the individual's psychological resources, including his/her level of self-esteem, not to mention previous experiences involving similar tasks. However, in the light of the data from previous studies, this result and interpretation is not quite so evident, which means that the reliance of the sense of efficacy on external factors with regard to the individual necessitates further exploration.

The second hypothesis concerned differences between literature teachers' sense of didactic efficacy, on the one hand, and the general sense of efficacy, on the other. Tables 2 and 3 show that the teachers demonstrated a higher sense of didactic efficacy than general efficacy, and that these differences were statistically significant.

Table 2. Statistical results for dependent samples: The Sense of Efficacy

Test and the Didactic Efficacy Test

\begin{tabular}{lccccc}
\hline & & Mean & $\mathrm{N}$ & Standard deviation & Standard error of the mean \\
\hline \multirow{2}{*}{$\begin{array}{l}\text { Pair } \\
1\end{array}$} & PDS & 2.3333 & 81 & .74162 & .08240 \\
\cline { 2 - 6 } & TPS & 2.0864 & 81 & .80928 & .08992 \\
\hline
\end{tabular}

Source: own research

Nominally, the differences between these statistical means are not large. However, they do not derive from a measurement error, but from other factors. Our study will not indicate which factors are responsible.

Table 3 Test T for dependent samples: The Sense of Efficacy Test and the Didactic Efficacy Test

\begin{tabular}{lcccccccc}
\hline $\begin{array}{l}\text { Pair: } \\
\text { TPS } \\
-\end{array}$ & Mean & $\begin{array}{c}\text { Standard } \\
\text { deviation }\end{array}$ & $\begin{array}{c}\text { Standard } \\
\text { error of the } \\
\text { mean }\end{array}$ & $\begin{array}{c}\text { 95\% } \\
\text { Lower } \\
\text { limit }\end{array}$ & $\begin{array}{c}95 \% \\
\text { Upper } \\
\text { limit }\end{array}$ & t & df & $\begin{array}{c}\text { Two-way } \\
\text { significance }\end{array}$ \\
\cline { 2 - 9 } & .024 & $\mathrm{p} 1.13$ & .12 & -.004 & .49 & 1.958 & 80 & .05 \\
\hline
\end{tabular}

Source: own research 
However, the theoretical viewpoint we accepted hints at a possible interpretation. It can be assumed that if Bandura was not mistaken in his claim regarding previous experiences as a factor contributing to the sense of efficacy, then the actual variety of experiences could generate a variety of sense of efficacy for different domains of life. Perhaps we are mistaken, moreover, in accepting the hidden and unverified assumption that personality traits are stable. It is these traits, as dispositional personal resources, that create indexes for the general sense of efficacy. It is difficult to resolve these issues at present. However it is also difficult to reject the hypothesis that they could change over time. This is one of the ways of interpreting the issue. By contrast, the other way allows us to maintain intact the idea of a stable set of resources, while drawing attention to the scope and complexity of the perspective that the participants adopted when they took our tests. To be sure, the statements in the TPS referred to a variety of (usually personal) life situations. The statement indices penetrated the participants' experience, which they had to recall so as to find a basis for providing responses. Thus, they referred to many experiences which the participants then remodeled to fit the shape of the test required responses. Briefly put, the responses might be the result of processing several experiences simultaneously, and could be a generalized version of all of them. On the other hand, the measurement of the sense of didactic efficacy in teaching literature refers to a narrow field of experience, even to singular events relatively isolated from the entire life experience of an individual. This difference could very well be responsible for the obtained results. Yet, this is not only a problem of processing experience in research situations. It is clearly a problem related to learning through experience. This socialization process refers to evaluating one's own experiences, which generate the sense of self-efficacy. A more unambiguous way of accomplishing the socialization process is possible, but it would require more uniform and less complex situations, to which undoubtedly occupational situations belong against the background of an individual's life situations. On the other hand, teachers' perception of their own actions might be saturated with positive self-esteem, which is necessary for upholding a positive vision of ourselves in occupational roles. And this might be why we obtained such results. If this is in fact the case, then Bandura's hypothesis regarding the micro-analytic sense of efficacy still seems difficult to undermine. 


\section{References}

Bandura, A. (1986). Social foundations of thought and action: A social cognitive theory. Englewood Cliffs, NJ: Prentice-Hall

Bandura A. (1994), Self-efficacy: Toward a unifying theory of behavioral change, In:

R.F. Baumeister (ed.), The self in Social Psychology, Ann Arbor Press, Philadelphia,

Bussey K., Bandura A. (1999), Social cognitive theory of gender development and differentation, Psychological Review No. 4

Cervone D. \& Pervin L.A. (2016). Personality: Theory and Research, $13^{\text {th }}$ Edition. Wiley

Chomczyńska-Rubacha M. \& Rubacha K. (2013) Educational strategies of teachers with various senses of efficacy. New Educational Review, Vol. 31 no. 1.

Rubacha K., Sirotová M. (2013) Poczucie skuteczności wychowawczej kandydatów na nauczycieli w Polsce i Słowacji.[Sense of upbringing effectivity of candidates for teachers in Poland and Slovakia]. Rocznik. Andragogiczny., T. 20 